\title{
Seasonality in clinical onset of Type 1 diabetes in Belgian patients above the age of 10 is restricted to HLA-DQ2/DQ8-negative males, which explains the male to female excess in incidence
}

\author{
I. Weets ${ }^{1}$ L. Kaufman ${ }^{2}$ - B. Van der Auwera ${ }^{1}$ L. Crenier ${ }^{3}$ - R. P. A. Rooman ${ }^{4}$ C. De Block ${ }^{5}$ K. Kasteels ${ }^{6}$

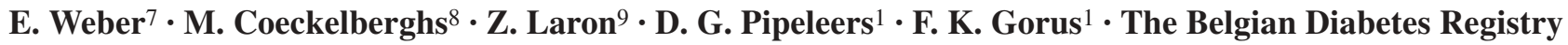 \\ ${ }^{1}$ Diabetes Research Center, Brussels Free University, Brussels, Belgium \\ 2 Department of Biomedical Statistics, Brussels Free University, Belgium \\ ${ }^{3}$ Department of Endocrinology, Erasmus Hospital, Brussels, Belgium \\ ${ }^{4}$ Department of Pediatrics, University of Antwerp, Edegem, Belgium \\ ${ }^{5}$ Department of Endocrinology, University of Antwerp, Edegem, Belgium \\ ${ }^{6}$ Department of Pediatrics, Catholic University of Leuven, Belgium \\ 7 Department of Endocrinology, Saint-Joseph Hospital, Avlon, Belgium \\ ${ }^{8}$ Department of Pediatrics, Paola Children's Hospital, Antwerp, Belgium \\ ${ }^{9}$ Endocrinology and Diabetes Research Unit, Schneider Children's Medical Center, Petah Tikva, Israel \\ ${ }^{10}$ Belgian Diabetes Registry, Brussels, Belgium
}

\begin{abstract}
Aims/hypothesis. Type 1 diabetes arises from an interplay between environmental and genetic factors. The reported seasonality at diagnosis supports the hypothesis that currently unknown external triggers play a role in the onset of the disease. We investigated whether a seasonal pattern is observed at diagnosis in Belgian Type 1 diabetic patients, and if so whether seasonality varies according to age, sex and genetic risk, all known to affect the incidence of Type 1 diabetes.

Methods. The seasonal pattern at clinical diagnosis was assessed in 2176 islet antibody-positive diabetic patients aged 0 to 39 years diagnosed between 1989 and 2000. Additional stratification was performed for age, sex and $H L A-D Q$ genotype.

Results. Overall, a significant seasonal pattern at clinical diagnosis of diabetes was observed $(p<0.001)$. More subjects were diagnosed in the period of November to February $(n=829)$ than during the period of June to September $(n=619)$ characterised by higher averages of maximal daily temperature and daily hours of sun-
\end{abstract}

shine. However, the seasonal pattern was restricted to patients diagnosed above the age of 10 (0-9 years: $p=0.398 ; 10-19$ years: $p<0.001 ; 20-29$ years: $p=0.003$; 30-39 years: $p=0.015$ ). Since older age at diagnosis is associated with a male to female excess and a lower prevalence of the genetic accelerator $H L A-D Q 2 / D Q 8$, we further stratified the patients aged 10 to 39 years $(n=1675)$ according to $H L A-D Q$ genotype and sex, and we found that the seasonal pattern was largely restricted to male subjects lacking $D Q 2 / D Q 8 \quad(n=748$; $p<0.001$ vs all others: $n=927 ; p=0.031$ ).

Conclusions/interpretation. In a subgroup of male patients diagnosed over the age of 10, the later stages of the subclinical disease process may be more driven by sex- and season-dependent external factors than in younger, female and genetically more susceptible subjects. These factors may explain the male to female excess in diabetes diagnosed in early adulthood.

Keywords Age Climate Environmental factors . Epidemiology $\cdot H L A-D Q \cdot$ Incidence $\cdot$ Seasonality Sex $\cdot$ Type 1 diabetes $\cdot$ Viral infections

Received: 21 October 2003 / Accepted: 28 January 2004

Published online: 26 March 2004

(C) Springer-Verlag 2004

F. K. Gorus (®)

Diabetes Research Center, Brussels Free University,

Laarbeeklaan 103, 1090 Brussels, Belgium

E-mail: Frans.Gorus@az.vub.ac.be

Tel.: +32-2-4775030, Fax: +32-2-4775047
Abbreviations: EURODIAB, Europe and Diabetes . GADA, glutamate decarboxylase antibodies . IA-2A, insulinoma-associated protein 2 antibodies . IAA, insulin autoantibodies · ICA, islet cell cytoplasmic antibodies 


\section{Introduction}

Immune-mediated Type 1 diabetes is a multifactorial disease in which destruction of beta cells is triggered by largely unknown environmental or lifestyle factors in genetically susceptible individuals $[1,2]$. The role of external factors is illustrated by the incomplete concordance rate (less than 50\%) observed in monozygotic twins, by the geographical variation in incidence of Type 1 diabetes, and by the worldwide increase of the disease in young children $[2,3,4,5,6$, 7]. Early introduction of cows' milk proteins, short duration of breastfeeding, rapid growth or weight gain, puberty, pregnancy, obesity, vitamin D deficiency, cold climate, psychological stress, maternal blood group incompatibility, dietary toxins and viral infections have all been proposed to initiate or promote diabetes, but none has emerged so far as the prime aetiological factor $[2,6,7,8,9]$.

Several epidemiological studies have described a seasonal pattern in the onset of juvenile diabetes, with a peak incidence in winter and a nadir in the warmer summer months $[10,11,12,13]$. This seasonal variation has been taken as an indirect argument in favour of the role of environmental factors, such as viral infections or cold climate, in the development of the disease. Studies by EURODIAB (Europe and Diabetes) in patients diagnosed under age 15 have shown heterogeneity in the seasonal pattern of clinical onset according to age at diagnosis and region [10, 13]. However, most cases of Type 1 diabetes are diagnosed in people over the age of $15[1,14]$. Moreover, the disease displays marked age-dependent heterogeneity in terms of incidence rate, inaugural clinical manifestation, biological markers and the proportion of males to females $[14,15,16]$. Indeed, compared with childhood-onset diabetes, adult-onset diabetes has a less severe clinical presentation with a striking male to female excess, in sharp contrast with other autoimmune diseases, and less biological evidence of islet autoimmunity $[14,15,16]$. This includes less prominent insulitis and better preserved beta cell mass [17], lower prevalences and levels of islet antibodies except for glutamate decarboxylase autoantibodies (GADA), and a lower frequency of the high-risk $H L A-D Q 2 / D Q 8$ genotype, a genetic accelerator associated with early onset of Type 1 diabetes and with a more rapid progression toward Type 1 diabetes in non-diabetic antibody-positive siblings $[18,19]$.

Therefore, we investigated whether the seasonal pattern of clinical onset of Type 1 diabetes is a general characteristic of immune-mediated diabetes or whether it is restricted to subgroups with older age at diagnosis, subgroups of males and/or subgroups with fewer genetic accelerators. The prospective registration of clinical and demographic data from Type 1 diabetic patients diagnosed under age 40 in Belgium, and the assessment of their initial biological characteristics (islet autoantibodies, $H L A-D Q$ genotype) during a 12-year period of activity allowed us to address this issue.

\section{Subjects and methods}

Subjects. Between 1 January 1989 and 31 December 2000, 3271 diabetic patients were prospectively registered by the Belgian Diabetes Registry through voluntary reporting by participating diabetologists. The patients were all diagnosed according to National Diabetes Data Group criteria [20], were aged between 0 and 39 years, and were resident in Belgium. Of the 3271 registered patients, 2176 (1242 male and 934 female) were finally included after verification of the following criteria (some patients had more than one exclusion criterion): (i) having primary diabetes (cases of gestational diabetes, secondary diabetes or diabetes of unknown type were excluded, $n=102$ ); (ii) being of Caucasian descent (European or northern African) (excluded: $n=132$ ); (iii) being resident in Belgium for at least 6 months prior to diagnosis (excluded: $n=0$ ); (iv) having available demographic data, and available blood samples, taken within 18 months of diagnosis, for DNA and auto-antibody analysis (excluded: $n=523$ ); (v) testing positive for at least one type of diabetes-associated autoantibody (including islet cell cytoplasm antibodies [ICA], insulin autoantibodies [IAA], insulinoma-associated protein 2 antibodies [IA-2A] and GADA; excluded, $n=414$ ) to establish the presence of immune-mediated Type 1 diabetes [21]. Comparison with a sub-region (Antwerp district) with near-complete case ascertainment (94\%) has demonstrated that the larger Belgian group of patients, with incomplete ascertainment ( $52 \%$ over the entire study period), is representative for the Belgian diabetic patients who were diagnosed below age $40[5,22]$.

We also stratified the sample group according to the presence or absence of $H L A-D Q$ susceptibility genotypes. DNA was extracted from K-EDTA blood, amplified and $H L A$ $D Q A 1 * D Q B 1 *$ genotyped as described previously [23]. Based on the comparison of HLA-DQA1-DQB1 genotypes in 1866 antibody-positive recent-onset diabetic patients aged under 40 years at diagnosis (recruited in Belgium between January 1989 and March 1999) and in 750 non-diabetic Belgian residents, the following genotypes were found to confer significant susceptibility to Type 1 diabetes in the Belgian population: (i) $D Q A 1 * 0501-D Q B 1 * 0201 / D Q A 1 * 0301-D Q B 1 * 0302(D Q 2 /$ $D Q 8)$; (ii) homozygosity for $D Q A 1 * 0301-D Q B 1 * 0302(D Q 8)$ or $D Q A 1 * 0501-D Q B 1 * 0201$ (DQ2); and (iii) $D Q A 1 * 0301$ $D Q B 1 * 0302(D Q 8)$ in combination with one of the neutral $D Q A 1 *-D Q B 1 *$ haplotypes (0100-0501/0604/0605, 01020201, 0102-0502, 0301-0201, 0301-0301, 0301-0303, 03010401, 0401-0402 or 0501-0302) [18]. In the present study, patients aged 10 to 39 years at diagnosis $(n=1675)$ were further stratified according to the presence $(n=418)$ or absence $(n=1257)$ of the highest risk $H L A-D Q 2 / D Q 8$ genotype preferentially associated with young age at diagnosis [18]. Furthermore, additional stratification was carried out according to the presence of one of the other susceptible genotypes $(D Q 2 / D Q 2$, $D Q 8 / D Q 8$ or $D Q 8$ in combination with a neutral genotype, not preferentially associated with young age at diagnosis; $n=538$ ) or the presence of one of the protective, rare or neutral genotypes $(n=719)$ as described previously [18].

For the duration of the study, monthly averages for daily maximal temperature and daily hours of sunshine in central Belgium (Zaventem) were obtained from the Royal Belgian Meteorological Institute (Brussels, Belgium).

The study was approved by the ethics committees of the Belgian Diabetes Registry and of the universities participating 
in its scientific projects. Informed consent was obtained from each subject and/or their parents in accordance with the Helsinki Declaration.

Immune and genetic markers. We measured ICA by indirect immunofluorescence assay using cryosections of freshly frozen human blood group $\mathrm{O}$ pancreas for substrate [19]. The results were expressed in Juvenile Diabetes Foundation units. We detected IAA, GADA and IA-2A by liquid-phase radiobinding assay using, respectively, recombinant human ${ }^{125}$ I-labelled insulin, ${ }^{35} \mathrm{~S}$-labelled intact GAD (65 $\mathrm{M}_{\mathrm{r}}$ isoform) and the ${ }^{35} \mathrm{~S}$-labelled intracellular domain of IA-2 (IA-2 ${ }_{\text {ic }}$ ) for tracer [19]. The cDNA of human GAD65 was kindly provided by Professor A. Lernmark (University of Washington, Seattle, Wash., USA) and the IA- $2_{\text {ic }}$ by Dr M. Christie (King's College, London, UK). The recombinant human insulin used for preparing insulin tracer was provided by Dr Schmidt (Humulin; Eli Lilly, Brussels, Belgium). Cut-off values for positivity for ICA ( $\geq 12$ Juvenile Diabetes Foundation units), IAA ( $\geq 0.6 \%$ tracer bound), GADA ( $\geq 2.6 \%$ tracer bound) and IA-2A ( $\geq 0.4 \%$ tracer bound) were established to secure $99 \%$ diagnostic specificity after omission of outlying values based on the analysis of 789 healthy control subjects [19]. The antibody assays performed repeatedly well in successive external quality control programmes (Immunology of Diabetes Workshops [24], proficiency testing of the University of Florida [Gainesville, Fla., USA] and of the Research Institute for Children [New Orleans, La., USA], and the Diabetes Antibody Standardization Program [25]). In the Immunology of Diabetes combinatorial islet autoantibody workshop, diagnostic sensitivity adjusted for $99 \%$ specificity amounted to $73 \%$ for ICA, $85 \%$ for GADA and $36 \%$ for IAA (IA-2A was not yet available in our laboratory at the time of the workshop [1995]). In the Diabetes Antibody Standardization Program in 2002, sensitivity reported at $90 \%$ specificity was $64 \%$ for IAA, $90 \%$ for GADA and $68 \%$ for IA-2A.

Statistical analysis. To evaluate seasonality in diagnosis of diabetes, the statistical significance of any deviation of the observed number of subjects from the expected number of subjects was calculated using the Roger's test [26]. This method assumes a sinusoidal pattern over the months of the year with a peak and a nadir that are 6 months apart, and provides a $\chi^{2}$ statistic on 2 degrees of freedom. The parameters describing the model $(\alpha$ and $\beta$ ) were determined by non-linear regression analysis. Data were also analysed after stratification for age at onset, sex and $H L A-D Q$ genotypes or haplotypes. We adjusted for variability of month length by transforming the observations into results for months of equal length (365/12 days). The amplitude of oscillation (expressed as a percentage) was calculated from the mean of the highest and lowest expected number of subjects, which was determined by the model. Statistical tests were two-tailed and were performed using Microsoft Excel 2000. We considered $p$ values of less than 0.05 to be statistically significant.

\section{Results}

A significant seasonal pattern at clinical diagnosis was observed in patients diagnosed under age 40 both when the entire patient group $(n=2176)$ with incomplete ascertainment was studied $(p<0.001$; Fig. 1a) and when the analysis was restricted to the smaller group of patients from the Antwerp district $(n=350)$

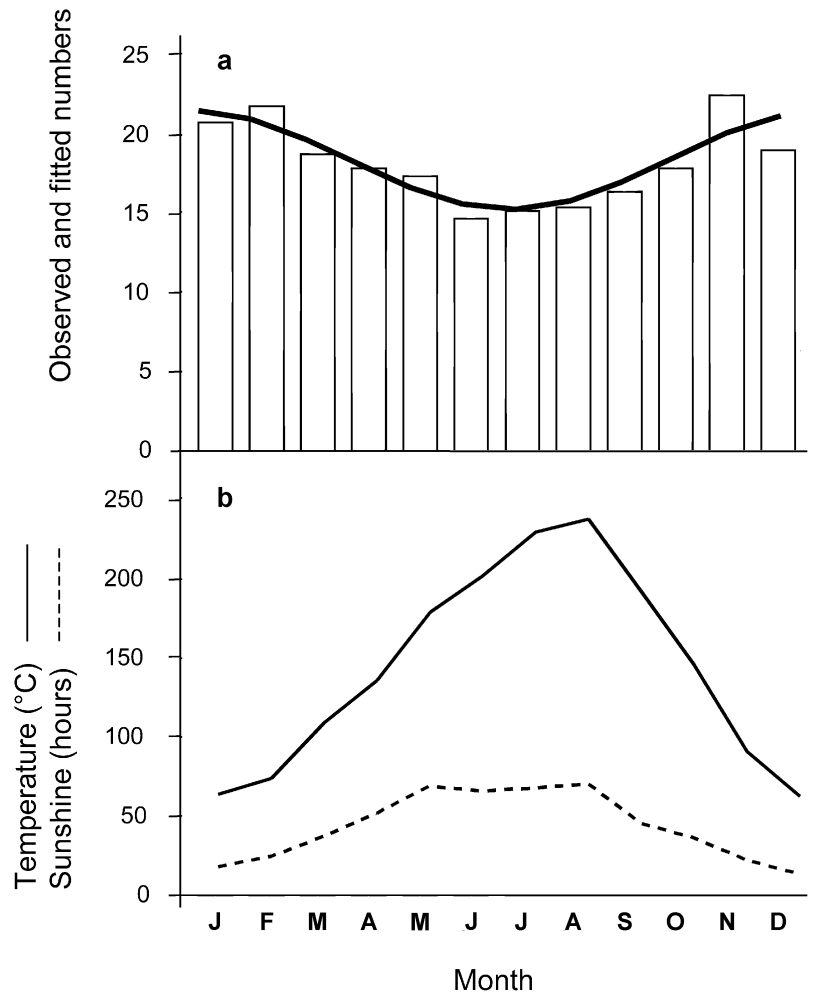

Fig. 1. Seasonal pattern at diagnosis in Type 1 diabetic patients aged 0-39 years and monthly averages of daily temperature and daily sunshine hours in central Belgium. a The bars represent the observed values transformed into results for months of equal length. The full line represents the fitted sinusoidal trend. b The full line represents the average maximum daily temperature and the dotted line represents the average daily sunshine hours observed for each month over the entire study period (1989-2000) in central Belgium (Zaventem, official data from the Royal Belgian Meteorological Institute). $n=2176$; cyclic trend: $\chi^{2}=32.8, p<0.001$.

with almost complete registration $[5,22](p=0.023$; not shown). Further analysis was performed on the larger Belgian group. More subjects were diagnosed in winter (November-February: $n=829$ ) than during the summer months (June-September: $n=619$ ). The amplitude of oscillation averaged $\pm 17.2 \%$ for the entire patient group. The monthly averages of maximal daily temperature and daily hours of sunshine observed during the study period (1989-2000) are inversely related to the monthly number of registered patients (Fig. 1b). Stratification for age at clinical onset (10-year strata) showed a significant seasonal pattern for diagnosis between age 10 and age 40, but not for diagnosis under age 10 (Fig. 2). The amplitude of oscillation averaged $\pm 19.8 \%$ in the age group 10 to 19 years, $\pm 20.1 \%$ in the group 20 to 29 years and $\pm 20.1 \%$ in the age group 30 to 39 years.

Because older age at diagnosis is associated with a striking male predominance and a lower prevalence of the $H L A-D Q 2 / D Q 8$ risk genotype $[14,15,16,18]$, all patients under age 10 at diagnosis were compared with an equal number of patients aged between 10 and 


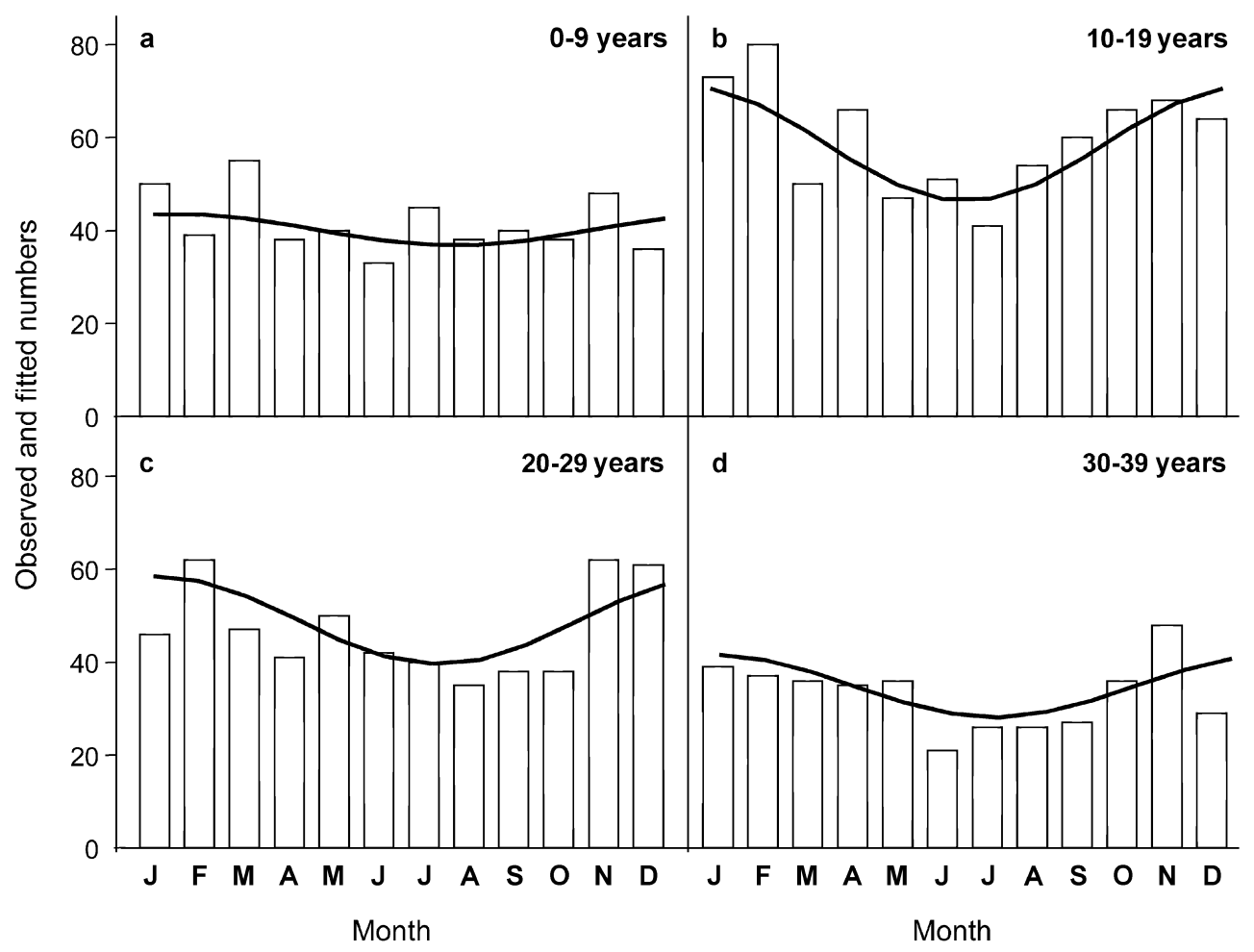

Fig. 2. Seasonality at diagnosis in Type 1 diabetes according to age at onset. The bars represent the observed values transformed into results for months of equal length. The line represents the fitted sinusoidal trend. a Subjects aged 0-9 years; $n=501$; cyclic trend: $\chi^{2}=1.8, p=0.398$. b Subjects aged $10-19$ years; $n=717$; cyclic trend: $\chi^{2}=15.4, p<0.001$. c Subjects aged 20-29 years; $n=560$; cyclic trend: $\chi^{2}=12.0, p=0.003$. d Subjects aged 30-39 years; $n=398$; cyclic trend: $\chi^{2}=8.4, p=0.015$

40 years after matching for sex and $H L A-D Q 2 / D Q 8$. The observed difference in seasonality persisted after matching for both confounders (0-9 years: $n=364$, $\chi^{2}=3.0, p=0.221 ; 10-39$ years: $n=364, \chi^{2}=8.0, p=0.018$; not shown). Seasonality was further studied in the patient group aged 10 to 39 years, which had a significant seasonal pattern at clinical diagnosis, after stratification according to sex and $H L A-D Q$ status. There was a significant seasonal pattern in male $\left(n=983 ; \chi^{2}=37.8\right.$, $p<0.001)$ but not in female $\left(n=692 ; \chi^{2}=4.9, p=0.086\right)$ patients. This sex-dependent difference persisted when all female patients aged 0 to 39 years were matched for age and $D Q 2 / D Q 8$ to an equal number of male patients (males: $n=934, \chi^{2}=20.4, \quad p<0.001$; females: $n=934$, $\chi^{2}=5.4, p=0.069$; not shown). Due to the preferential occurrence of a seasonal pattern at diagnosis in male patients, the male to female excess is mainly restricted to the high incidence period (November-February: 1.66; June-September: 1.06 ; $p=0.001$ ). In addition, regardless of sex, seasonality in those diagnosed over the age of 10 was significant in the absence of the $D Q 2 / D Q 8$ genotype $\left(n=1257 ; \chi^{2}=27.2, p<0.001\right)$ but only borderline in carriers of $D Q 2 / D Q 8 \quad(n=418$; $\chi^{2}=7.5, p=0.024$; not shown). Furthermore, we com- pared the seasonal pattern in patients carrying susceptible $H L A-D Q$ genotypes other than $D Q 2 / D Q 8$ (as identified in the Belgian population) [18] with that of patients with a protective, rare or neutral genotype (see Methods for genotype classification) [18]. In both groups a significant seasonality was found (susceptible genotypes other than $D Q 2 / D Q 8: n=538, \chi^{2}=15.8, p<0.001$; protective/rare/neutral HLA-DQ genotypes: $n=719$, $\chi^{2}=14.1, p<0.001$; not shown).

To further investigate the association between sex and $H L A-D Q$ genotype, we examined the seasonality of Type 1 diabetes at diagnosis after combined stratification for sex and for the presence or absence of the $D Q 2 / D Q 8$ genotype (Fig. 3). We observed highly significant seasonality in male patients without the $D Q 2 / D Q 8$ genotype, but in male subjects carrying the $D Q 2 / D Q 8$ genotype as well as in female subjects with or without the $D Q 2 / D Q 8$ genotype, we either did not find any significant seasonal pattern, or we found patterns with only borderline significance. To eliminate the possibility that the absence of a seasonal pattern in these subgroups was the consequence of a lower number of subjects, we combined the three groups without apparent seasonal pattern (Fig. 3a,c,d). At variance with the significant seasonal pattern of male patients without $D Q 2 / D Q 8\left(n=748 ; \chi^{2}=23.9, p<0.001\right.$; Fig. 3b), the larger combined group consisting of female subjects and male carriers of $D Q 2 / D Q 8$ displayed no clear-cut seasonal pattern of clinical onset $\left(n=927 ; \chi^{2}=6.9, p=0.031\right)$. To further document heterogeneity according to $D Q 2 / D Q 8$ genotype, we adjusted for the possible confounding effects of age and sex. All patients carrying $D Q 2 / D Q 8$ (aged $0-39$ years) were matched for these variables to an equal number 


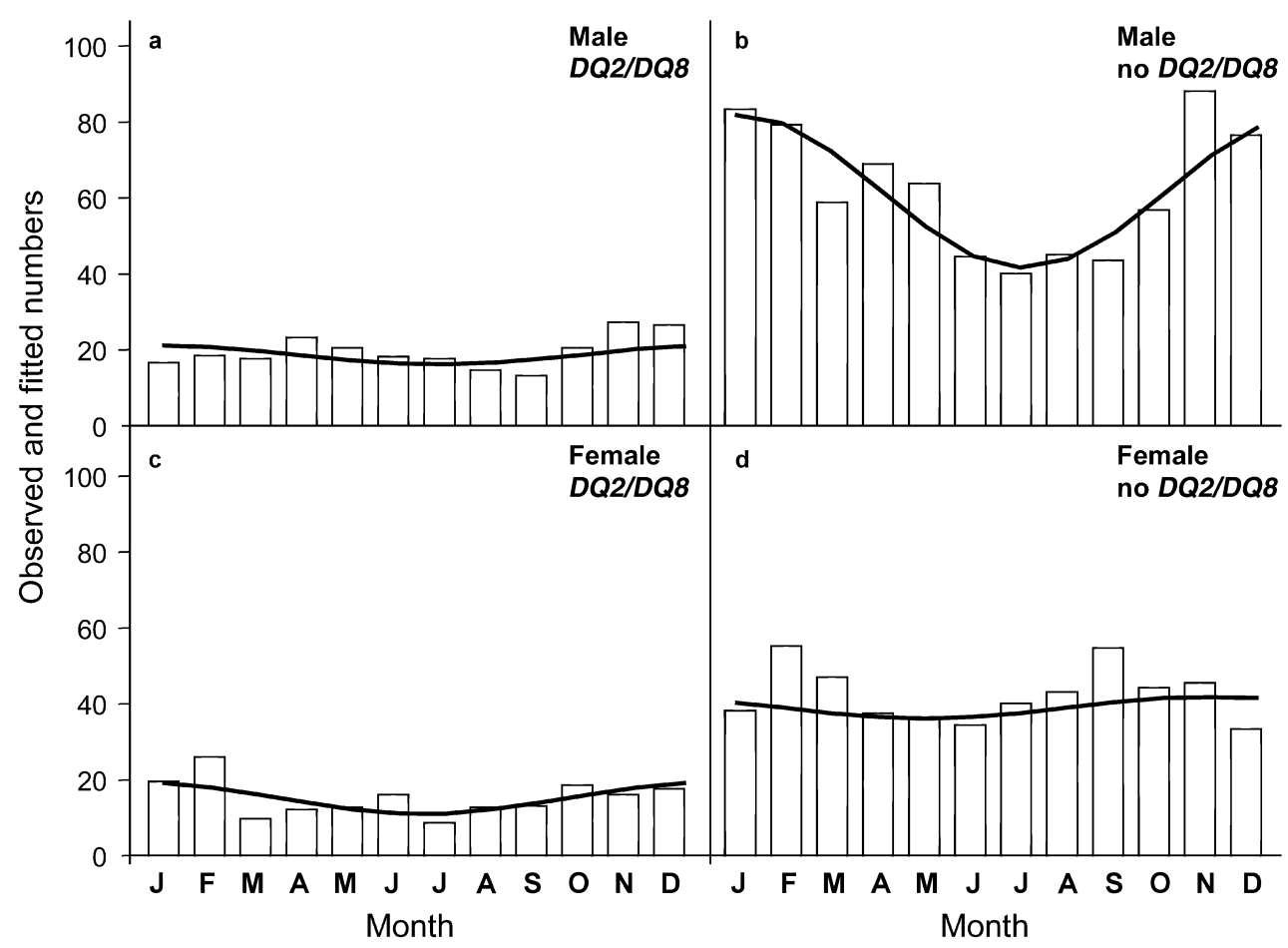

Fig. 3. Seasonality at diagnosis in Type 1 diabetes patients aged 10-39 years according to sex and to the presence or absence of the high-risk $H L A-D Q 2 / D Q 8$ genotype. The bars represent the observed values transformed into results for months of equal length. The line represents the fitted sinusoidal trend. a Male subjects aged 10-39 years carrying $D Q 2 / D Q 8 ; n=235$; cyclic trend: $\chi^{2}=0.8, p=0.679$ b Male subjects aged $10-39$ years lacking $D Q 2 / D Q 8 ; n=748$; cyclic trend: $\chi^{2}=23.9, p<0.001$ c Female subjects aged $10-39$ years carrying $D Q 2 / D Q 8 ; n=183$; cyclic trend: $\chi^{2}=6.7, p=0.035$ d Female subjects aged 10-39 years lacking $D Q 2 / D Q 8 ; n=509$; cyclic trend: $\chi^{2}=1.3, p=0.520$

of patients lacking $D Q 2 / D Q 8$. A significant seasonal pattern persisted in the absence of $D Q 2 / D Q 8(n=607$; $\left.\chi^{2}=9.1, p=0.010\right)$ but not when it was present $(n=607$; $\chi^{2}=4.0, p=0.136$; not shown). In addition, in a group of 380 antibody-negative patients with an $H L A-D Q$ genotype other than $D Q 2 / D Q 8$, more patients under age 40 were diagnosed in winter than in summer during the same period (cyclic trend: $\chi^{2}=8.1, p=0.018$ ). However, this group was too small to look for the possible confounding effects of age and sex.

\section{Discussion}

Effects of age, sex and HLA-DQ genotype on seasonal pattern at diagnosis in immune-mediated diabetes. Consistent with previous reports [10, 11, 12, 13], we found a significant seasonal pattern at clinical diagnosis of immune-mediated diabetes in Belgium, with peak values between November and February. In contrast to previous reports focusing on diabetes diagnosed in patients under age 15 , the present study has also investigated patients diagnosed between 15 and 40 years of age. In order to avoid variable admixture of Type 2 or idiopathic Type 1 diabetes with uncertain aetiology, all patients were selected on the basis of antibody positivity as proof of the presence of an immune-mediated disease process. Consistent with observations from EURODIAB [10,13], the seasonal pattern was comparable with a sinusoidal curve, and the observed amplitude of oscillation averaged $\pm 17.2 \%$. At variance with EURODIAB, where age groups 0 to 4,5 to 9 and 10 to 14 were compared, seasonality was only significant above age 10 . This discrepancy is possibly due to a lower number of observations under age 10 in Belgium compared with in the European study, but may also be due to regional differences as described in the EURODIAB studies [13]. Overall, our results confirm and extend other reports that seasonality of Type 1 diabetes onset increases with age at diagnosis [10, 13, 27].

Compared with juvenile Type 1 diabetes, adult-onset disease ( $\geq 15$ years) is characterised by a striking male predominance and a lower frequency of the high-risk $H L A-D Q 2 / D Q 8$ genotype. This genotype is the strongest known genetic accelerator associated with early onset of Type 1 diabetes and with more rapid progression toward Type 1 diabetes in nondiabetic antibody-positive siblings [1, 18, 19]. We therefore investigated whether the apparent age dependency of seasonality could be due to differences in seasonal pattern in terms of sex- and/or HLA-DQlinked genetic predisposition rather than due to differences in age at diagnosis. Our results indicate that seasonality at diagnosis is not a general characteristic of immune-mediated diabetes but seems largely restricted to older male patients lacking the highest risk 
genotype $H L A-D Q 2 / D Q 8$. The data suggest that in a subgroup of male pre-diabetic subjects, the underlying pathological process is driven to a greater extent by environmental or lifestyle factors than in other patients, as further supported by (i) the observation of an equally large male to female excess in age-matched adult-onset Type 2 patients [16]; (ii) the association between GADA positivity and being overweight in male but not in female non-diabetic first degree relatives of Type 1 diabetic patients [16]; (iii) the secular trend toward decreasing age at diagnosis in male but not in female patients in Belgium [5]; and (iv) the existence of a seasonal pattern at diagnosis in antibodynegative patients lacking $D Q 2 / D Q 8$ in this study. Our observations are also compatible with results from EURODIAB describing a less-pronounced seasonality in Scandinavian regions with a high incidence of childhood-onset diabetes and a high prevalence of susceptible $H L A-D Q$ genotypes $[10,13,28]$.

Putative external factors contributing to the seasonal pattern in males. It has been proposed that several external aetiological factors influence the incidence of Type 1 diabetes. These include viral infections, maternal blood group incompatibility, dietary toxins, early introduction of cows' milk, avoidance of breastfeeding, vitamin D deficiency, obesity, cold climate, puberty, pregnancy, rapid growth or weight gain, and psychological stress $[6,8,15,29,30,31,32]$. The diversity of these factors raises the question of whether they act through a limited number of common pathways. Since the destructive insulitis of Type $1 \mathrm{di}-$ abetes is believed to result from changes in the beta cells and/or the immune system, aetiological external factors are likely to directly or indirectly alter at least one of these cell systems $[17,33]$. The male to female excess in Type 1 diabetes contrasts sharply with the striking female preponderance in other autoimmune diseases [34]. As there is growing evidence that an increased metabolic burden drives the disease process underlying immune-mediated diabetes $[7,35,36]$, and since there is also a large male bias in Type 2 diabetes diagnosed in early adulthood [16], it is tempting to speculate that the metabolic component of Type 1 diabetes may play an important role in the bias. Most of the observed risk factors (e.g. a wide range of viral infections, and perinatal stressful events such as maternal blood group incompatibility, psychological stress, rapid growth, obesity, puberty, pregnancy, cold climate) may have as a common denominator that they increase the metabolic strain on the beta cells [29, 36, 37]. Other factors, such as vitamin D deficiency, may act preferentially on the immune system [6].

The restriction of the male excess to the winter months suggests that one or several aetiological factors display seasonal variation, and that they are more persistent in men owing to their higher susceptibility or owing to a higher level of protection in women. In view of the observed north-south gradient in the incidence of Type 1 diabetes throughout Europe, and the worldwide observation of an incidence peak during the winter months, less daylight and low ambient temperature as well as their metabolic concomitants, e.g. higher vitamin $\mathrm{D}$ requirements, higher food intake or less exercise, may play a precipitating role $[6,7,31$, 32]. In line with this assumption, we found that the monthly averages of maximal daily temperature and daily hours of sunshine were inversely related to the number of new patients per month in Belgium. Interestingly, the incidence of diabetes in non-obese diabetic mice was lower when animals were kept at a higher ambient temperature [38]. It is conceivable that male subjects, with their overall greater height and weight and/or more central fat distribution, are selectively sensitive to the additional metabolic burden caused by many of the external risk factors. Seasonal variation in testosterone levels and waist-to-hip ratio was noted in Norwegian men, with peak values in December and a nadir in August [39]. Moreover, unlike androgens, oestrogens either alone or in combination with progestins may have a beneficial effect on blood glucose levels in women [40]. Viral infections, vitamin $\mathrm{D}$ requirements and psychological stress are also likely to present a seasonal pattern.

In conclusion, the presence of a seasonal pattern at diagnosis of Type 1 diabetes is largely restricted to male patients lacking the $H L A-D Q 2 / D Q 8$ high-risk genotype. Sex-related differences in incidence, age distribution and seasonality of Type 1 diabetes may be due to a variable contribution of genetic and external aetiological factors in the disease process in terms of age, sex and season. Future studies that aim to identify environmental factors may benefit from focusing on patient subgroups with marked seasonality at diagnosis, e.g. male subjects over the age of 10 lacking $D Q 2 / D Q 8$. In risk groups such as first-degree relatives, these subjects may also become the best targets for primary prevention of Type 1 diabetes.

Acknowledgements. The present work was supported by the Fund for Scientific Research (Flanders, Belgium; grants 3-0113-97, 3-0456-99 and G-0319-01, and Levenslijn-Diabetes project 7.0021.96) and by Bayer (Leverkusen, Germany), Life Scan (Beerse, Belgium), Novo Nordisk (Bagsvaerd, Denmark), Ortho Clinical Diagnostics(Beerse, Belgium) and Roche (Vilvoorde, Belgium). The central unit of the Belgian Diabetes Registry is supported financially by grants from the Ministries of Public Health of the Flemish and French Community. We thank the Flemish Diabetes Association, the Belgian Diabetes Association (French-speaking branch) and the following members of the Belgian Diabetes Registry for their invaluable help in recruiting diabetic patients and first-degree relatives and/or in the handling of blood samples: P. Abrams, E. Anckaert, P. Arnouts, E. Balasse, D. Ballaux, J.-P. Baeyens, D. Beckers, H. Becq, A. Beirinckx, J. Beirinckx, M. Bex, A. Bocquet, A. Bodson, R. Bouillon, J. Bourguignon, H. Bossaert, M. Bouquegneau, H. Brussaard, M. Buysschaert, M. Cardon, A. Carlier, K. Casteels, E. Cavatorta, A. Chachati, C. Claeys, L. Claeys, M. Claeys, M. Cnop, P. Cochez, M. Coeckelberghs, 
I.M. Colin, J.-L. Coolens, P. Coremans, B. Corvilain, P. Couck, F. Coucke, W. Coucke, E. Couturier, R. Craen, A. Crapé, L. Crenier, P. Damoiseaux, C. Daubresse, J.-C. Daubresse, C. De Block, K. Decochez, P. Decraene, I. De Feyter, F. Defoer, R. De Hauwere, I. De Leeuw, K. De Keyser, B. Delgrange, R. Demaeseneer, L. Derdelinckx, J. De Schepper, D. Désir, G. De Wasch, S. Deweer, L. Dooms, H. Dorchy, M. Du Caju, J. Ducobu, E. Duvivier, F. Duyck, A. Dysseleer, L. Emsens, C. Ernould, C. Evenepoel, A. Eykens, A. Fassotte, F. Féry, R. Fils, N. Gaham, K. Garmijn, J. Gérard, I. Geronooz, P. Gillard, C. Gillet, M. Giri, F. Gorus, J. Guiot, A. Haemers, S. Haemers, F. Hay, C. Hendrieckx, C. Herbaut, G. Heremans, F. Heureux, G. Hubermont, J. Huyghe, V. Immegeers, B. Jandrain, P. Jopart, B. Keymeulen, Y. Kockaerts, G. Krzentowski, K. Laga, E. Lagasse, G. Lamberigts, M.-C Lebrethon, P. Lefèbvre, M. Letiexhe, B. Leus, F. Lienart, T-T. Lim, C. Litvine, K. Logghe, M. Maes, W. Maes, M. Marchal, P. Mariën, C. Mathieu, Y. Maus, J. Mockel, J. Monballyu, G. Moorkens, E. Muls, W. Musch, P. Nachtegaele, D. Nicolaij, F. Nobels, A. Nollet, F. Paciorkowski, N. Paquot, F. Peiffer, M.-C. Pelckmans, H. Penninckx, O. Peters, J.-C. Philips, M. Pieron, D. Pipeleers, L. Poelmans, A. Purnode, C. Remy, C. Righes, D. Rocour-Brumioul, R. Rooman, R. Rottiers, D. Scarniere, A. Scheen, E. Schils, I. Schoemaker, M. Schueman, F. Schuit, J. Schutyser, N. Seret, J.-C. Sodoyez $\dagger$, G. Somers $\dagger$, M.-P. Stassen, M. Struelens, P. Taelman, L. Terriere, J. Teuwen, G. Thenaers, G. Thiry-Counson, J. Tits, I. Truyen, J. Unger, K. Van Acker, E. Van Aken, P. Van Belle, P. Van Crombrugge, H. Van De Cauter, E. Vandemeulebroucke, M. Vandenbroucke, A. Van Den Bruel, E. Vandenbussche, B. Van der Auwera, M. Vanderijst, H. Vanderstappen, E. Vanderstraeten, D. Van Doorn, E. Van Fleteren, L. Van Gaal, L. Van Garsse, E. Van Gastel, D. Van Gijsegem, M. Van Helvoirt, S. Van Imschoot, S. Vanneste, D. Vannimmen, C. Van Parijs, P. Van Rooy, C. Van Winghem, R. Verbiest, C. Vercammen, A. Verhaegen, G. Verhaert, I. Verschraegen,

J. Verschuere, E. Weber, I. Weemaes, G. Wyffels.

We are indebted to N. Alaerts, V. Baeten, M. Bodson, M. Carpentier, A. Ceusters, V. Claessens, N. Christophe, E. De Man, A. Demarré, T. Demesmaeker, S. De Neve, L. De Pree, S. Exterbille, T. Ghysels, P. Goubert, C. Groven, A. Hutse, A. Ivens, D. Kesler, C. Lauwers, F. Lebleu, J. Michiels, H. Morobé, E. Quartier, G. Schoonjans, H. Thomas and J. Vertommen for excellent technical assistance.

\section{References}

1. Krolewski AS, Warram JH, Rand LI, Kahn CR (1987) Epidemiologic approach to the etiology of type 1 diabetes mellitus and impaired glucose tolerance in adults. N Engl J Med 317:1390-1398

2. Leslie DRG, Elliott RB (1994) Early environmental events as a cause of IDDM. Evidence and implications. Diabetes 43:843-850

3. Onkamo P, Väänänen S, Karvonen M, Tuomilehto J (1999) Wordwide increase in incidence of type 1 diabetes - the analysis of data on published incidence trends. Diabetologia 42:1395-1403

4. EURODIAB ACE Study Group (2000) Variation and trends in the incidence of childhood diabetes in Europe. Lancet 355:873-876

5. Weets I, De Leeuw IH, Du Caju MVL et al. (2002) The incidence of type 1 diabetes in the age group 0-39 years has not increased in Antwerp (Belgium) between 1989 and 2000. Evidence for earlier disease manifestation. Diabetes Care 25:840-846
6. Soltész G (2003) Diabetes in the young: a paediatric and epidemiological perspective. Diabetologia 46:447-454

7. Dahlquist G (1993) Etiological aspects of insulin-dependent diabetes mellitus: an epidemiological perpective. Autoimmunity 15:61-65

8. Åkerblom HK, Vaarala O, Hyoty H, Ilonen J, Knip M (2002) Environmental factors in the etiology of type 1 diabetes. Am J Med Genet 115:18-29

9. Eurodiab Substudy 2 Study Group (2002) Rapid early growth is associated with increased risk of childhood type 1 diabetes in various European populations. Diabetes Care 25:1755-1760

10. Green A, Patterson CC (2001) Trends in the incidence of childhood-onset diabetes in Europe 1989-1998. Diabetologia 44 [Suppl 3]:B3-B8

11. Karvonen M, Jantti V, Muntoni S et al. (1998) Comparison of the seasonal pattern in the clinical onset of IDDM in Finland and Sardinia. Diabetes Care 21:1101-1109

12. Joner G, Søvik O (1989) Increasing incidence of diabetes mellitus in Norwegian children 0-14 years of age 1973-1982. Diabetologia 32:79-83

13. Lévy-Marchal C, Patterson C, Green A (1995) Variation by age group and seasonality at diagnosis of childhood IDDM in Europe. Diabetologia 38:823-830

14. Gorus FK, the Belgian Diabetes Registry (1997) Diabetes registries and early biological markers of insulin-dependent diabetes mellitus. Diabetes Metab Rev 4:247-274

15. Gale EAM, Gillespie KM (2001) Diabetes and gender. Diabetologia 44:3-15

16. Weets I, Van der Auwera BJ, Schuit FC et al. (2001) Male-to-female excess in diabetes diagnosed in early adulthood is not specific for the immune-mediated form nor is it HLA-DQ restricted: possible relation to increased body mass index. Diabetologia 44:40-47

17. Pipeleers D, Ling Z (1992) Pancreatic $\beta$-cells in insulindependent diabetes. Diabetes Metab Rev 8:209-227

18. Van der Auwera B, Schuit FC, Weets I et al. (2002) Relative and absolute HLA-DQA1-DQB1-linked risk for developing type 1 diabetes before age 40 years in the Belgian population-implication for future prevention studies. Hum Immunol 63:40-50

19. Decochez K, De Leeuw IH, Keymeulen B et al. (2002) IA-2 autoantibodies predict impending type 1 diabetes in siblings of patients. Diabetologia 45:1658-1666

20. National Diabetes Data Group (1979) Classification and diagnosis of diabetes mellitus and other categories of glucose intolerance. Diabetes 28:1039-1057

21. The Expert Committee on the Diagnosis and Classification of Diabetes Mellitus (1997) Report of the Expert Committee on the Diagnosis and Classification of Diabetes Mellitus. Diabetes Care 20:1183-1197

22. Vandewalle CL, Coeckelberghs MI, De Leeuw IH et al. (1997) Epidemiology, clinical aspects, and biology of IDDM patients under age 40 years. Diabetes Care 20:1556-1561

23. Van der Auwera BJ, Schuit FC, Lyaruu I et al. (1995) Genetic susceptibility for insulin-dependent diabetes mellitus in Caucasians revisited: the importance of diabetes registries in disclosing interactions between HLA-DQ- and insulin gene-linked risk. J Clin Endocrinol Metab 80:25672573

24. Verge CF, Stenger D, Bonifacio E et al. (1998) Combined use of autoantibodies (IA2ab, GADab, IAA, ICA): combinatorial islet autoantibody workshop. Diabetes 47:1857-1866

25. Bingley P, Bonifacio E, Mueller P (2003) Diabetes Autoantibody Standardization Program: first assay proficiency evaluation. Diabetes 52:1128-1136 
26. Roger JH (1977) A significance test for cyclic trends in incidence data. Biometrika 64:152-155

27. Verge C, Silink M, Howard NJ (1994) The incidence of childhood IDDM in New South Wales, Australia. Diabetes Care 17:693-696

28. Rønningen KS, Keiding N, Green A; EURODIAB ACE Study Group. Europe and Diabetes (2001) Correlations between the incidence of childhood-onset type 1 diabetes in Europe and HLA genotypes. Diabetologia 44 [Suppl 3]: B51-B59

29. Zimmet PZ (1995) The pathogenesis and prevention of diabetes in adults. Diabetes Care 18:1050-1064

30. Jun HS, Yoon JW (2003) A new look at viruses in type 1 diabetes. Diabetes Metab Res Rev 19:8-31

31. Patterson CC, Dahlquist G, Soltész G, Green A; EURODIAB ACE Study Group. Europe and Diabetes (2001) Is childhood-onset type I diabetes a wealth-related disease? An ecological analysis of European incidence rates. Diabetologia 44 [Suppl 3]:B9-B16

32. Dahlquist G, Mustonen L (1994) Childhood onset diabetes - Time trends and climatological factors. Int J Epidemiol 23:1234-1241

33. Homo-Delarche F, Boitard C (1996) Autoimmune diabetes: the role of the islets of Langerhans. Immunol Today $17: 456-460$
34. Whitacre CC, Reingold SC, O'Looney PA (1999) A gender gap in autoimmunity. Science 283:1277-1278

35. Gorus FK, Pipeleers DG; Belgian Diabetes Registry (2001) Prospects for predicting and stopping the development of type 1 diabetes. Best Pract Res Clin Endocrinol Metab 15:371-389

36. Wilkin TJ (2001) The accelerator hypothesis: weight gain as the missing link between Type I and Type II diabetes. Diabetologia 44:914-922

37. Gorus FK, Weets I, Pipeleers D (2002) — to: Wilkin (2001) The accelerator hypothesis: weight gain as the missing link between type I and type II diabetes. Diabetologia 45:288289

38. Williams AJ, Krug J, Lampeter EF et al. (1990) Raised temperature reduces the incidence of diabetes in the NOD mouse. Diabetologia 33:635-637

39. Svartberg J, Rolf J, Sundsfjord J et al. (2003) Seasonal variation of testosterone and waist-to-hip ratio in men: the Troms $\varnothing$ study. J Clin Endocrinol Metab 88:30993104

40. Kanaya AM, Herrington D, Vittinghoff E et al. (2003) Glycemic effects of postmenopausal hormone replacement therapy: the Heart and Oestrogen/progestin Replacement Study. Ann Intern Med 138:1-9 